Check for updates

Cite this: RSC Adv., 2017, 7, 55567

\title{
A colorimetric and far-red fluorescent probe for the highly sensitive detection of silver( 1$) \dagger$
}

\author{
Yong-jun Wang, ${ }^{\star a}$ Jing-gong Liu, ${ }^{\text {tb }}$ Hui-ya Tan, ${ }^{a}$ Jin-wu Yan (DD *a and Lei Zhang ${ }^{* a}$ \\ Herein, a potential colorimetric and far-red fluorescent probe DCPS-1 for $\mathrm{Ag}^{+}$was rationally developed \\ based on a dicyanomethylene- $4 \mathrm{H}$-chromene chromophore. Its prominent and distinct changes in both \\ color and fluorescence enable the on-site and naked-eye detection of $\mathrm{Ag}^{+}$easily and quickly, \\ accompanied with excellent sensitivity. No absorption and fluorescence response could be observed \\ towards other metal ions. The fluorescence intensity of this probe showed a linear response to $\mathrm{Ag}^{+}$in \\ the concentration range of $0-10 \mu \mathrm{M}$ with a detection limit of $21.1 \mathrm{nM}$. In addition, this probe had low \\ toxicity to cells and gave distinct fluorescence changes in cell imaging. All these results demonstrate its \\ promising application prospects for $\mathrm{Ag}^{+}$sensing in both environmental and biology fields.
}

Received 30th October 2017

Accepted 1st December 2017

DOI: $10.1039 / c 7 r a 11933 j$

rsc.li/rsc-advances

be a cumulative toxin, but also interact with and displace

\section{Introduction}

With the development of modern science and technology, heavy and transition metals have been widely applied in many fields such as chemistry, electrical and electronic materials, biology and environmental science. ${ }^{1-5}$ Gold, platinum, palladium and silver play a very vital role in modern society. Gold, platinum and palladium are precious metals; they are widely used in the chemical industry, materials science, the biomedical field, jewellery, etc. However, these precious metal ions have some negative effects. They can damage the liver, kidneys and cause gene alteration, autoimmune disorders, a variety of cellular dysfunction processes $e t c .^{6-10}$

Silver, as a very important precious mental, plays an important role in many fields such as ornaments, glass, fine chemicals, and nano-materials, as well as in monetary manufacturing. However, with the development of modern industry, more and more $\mathrm{Ag}^{+}$is released which makes water sources polluted and further affects the food and agriculture. ${ }^{11,12}$ Silver also has some negative biological effects, such as silver ions inactivate sulfhydryl enzymes, bind with various metabolites and organ failure. ${ }^{13-15}$ Besides, Ag-exposure to the silver environment for a long time can lead to anemia, heart dilation, poor growth, embryotoxicity, and even cirrhosis of the liver. ${ }^{16,17}$ Blood silver and urine silver excretion are useful indices of human silver exposure, silver ion is not only known to

${ }^{a}$ School of Biology and Biological Engineering, South China University of Technology, Guangzhou, P. R. China.E-mail:yjw@scut.edu.cn; lzhangce@scut.edu.cn; Tel: +8620 39380678

${ }^{b}$ The Second Affiliated Hospital of Guangzhou University of Chinese Medicine, Guangdong Provincial Academy of Chinese Medical Sciences, Guangzhou, 510006, P. R. China

$\dagger$ Electronic supplementary information (ESI) available: Synthesis and characterization of DCPS-1, experimental procedures, and supplemental spectra and graphs. See DOI: 10.1039/c7ra11933j essential metal ions like $\mathrm{Ca}^{2+}$ and $\mathrm{Zn}^{2+}$ in hydroxyapatite in bone. ${ }^{18}$ Also, silver ion shows a rich biological chemistry, serving as a widely used antibacterial agent, and a transcriptional initiator in plants and mammals. ${ }^{19}$ Therefore, the need for a highly sensitive and selective detection above ions in vivo is very significant.

Due to the continual concern over silver in the environment and health, several available methods have been used for the detection of $\mathrm{Ag}^{+}$, such as atomic absorption spectroscopy (AAS), inductively coupled plasma/mass spectrometry (ICP-MS), inductively coupled plasma/atomic emission spectrometry (ICP-AES). However, these traditional methods suffer from time and money-consuming, and nonpocketable. ${ }^{20,21}$ Therefore, optical fluorescent probes, including colorimetric or fluorescent probe for sensitive and selective detection of heavy and transition metal ions have received significant attention in recent years. ${ }^{22-25}$ Especially the fluorescent probes with far-red to nearinfrared (NIR) emission are extremely appropriate for bioimaging because of deep penetration and minimum autofluorescence. ${ }^{26,27}$ Fluorescent probes have displayed outstanding properties such as simplicity, high sensitivity, and high detection limits compared with the traditional methods. Therefore, the development of fluorescent probe for the detection of $\mathrm{Ag}^{+}$with high selectivity and sensitivity is urgently desirable. In particular, colorimetric and far-red fluorescent dual probes with favourable sensitivity, selectivity and costefficiency are in urgent demand for practical applications. ${ }^{28,29}$

The mechanism of these fluorescent probes for the selective detection of $\mathrm{Ag}^{+}$is that $\mathrm{Ag}^{+}$shows a high tendency to coordinate with soft Lewis base such as sulfur containing ligand due to the soft Lewis acid character. As a part of work for $\mathrm{Ag}^{+}$recognition, we designed a dicyanomethylene- $4 \mathrm{H}$-chromene-based fluorescence probe (DCPS-1) for the selective detection of $\mathrm{Ag}^{+}$, this 
<smiles>CCSCCN(CCSCC)c1ccc(/C=C/C2=CC(=C(C#N)C#N)c3ccccc3O2)cc1</smiles>

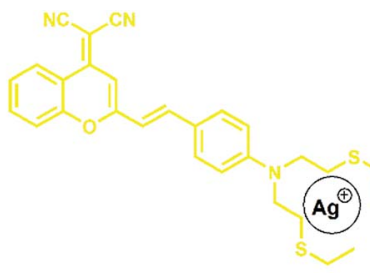

Scheme 1 Chemical structures of fluorescent probe DCPS-1 and its complex with $\mathrm{Ag}^{+}$.

probe would form complex with $\mathrm{Ag}^{+}$, accompanied with color change and turn-off far-red emission (Scheme 1). Some fluorescent probes based on the turn-off mechanism have been reported in recent years. ${ }^{30-34}$

\section{Results and discussion}

The designed probe DCPS-1 was prepared by the reaction of (2-methyl-4H-1-benzopyran-4-ylidene)-propanedinitrile and 4-[bis[2-(ethylthio)ethyl]amino]-benzaldehyde, and the detailed synthetic procedure is described in Scheme 1 in the ESI. $\dagger$ With probe DCPS-1 in hand, we first performed UV-vis and fluorescence experiments to test the selectivity of probe DCPS-1 $(5 \mu \mathrm{M})$ for $\mathrm{Ag}^{+}(25 \mu \mathrm{M})$, while 10 equivalent various other metal ions $\left(\mathrm{Fe}^{3+}, \mathrm{Hg}^{2+}, \mathrm{K}^{+}, \mathrm{Na}^{+}, \mathrm{Pb}^{2+}, \mathrm{Ca}^{2+}, \mathrm{Mg}^{2+}, \mathrm{Cu}^{2+}, \mathrm{Cu}^{+}, \mathrm{Ni}^{2+}, \mathrm{Co}^{2+}, \mathrm{Ba}^{2+}\right.$, $\mathrm{Zn}^{2+}$ and $\mathrm{Mn}^{2+}$ ) in the $\mathrm{MeOH}$ solution respectively. As shown in Fig. 1, as shown in Fig. 1A, the absorption band of probe DCPS-1
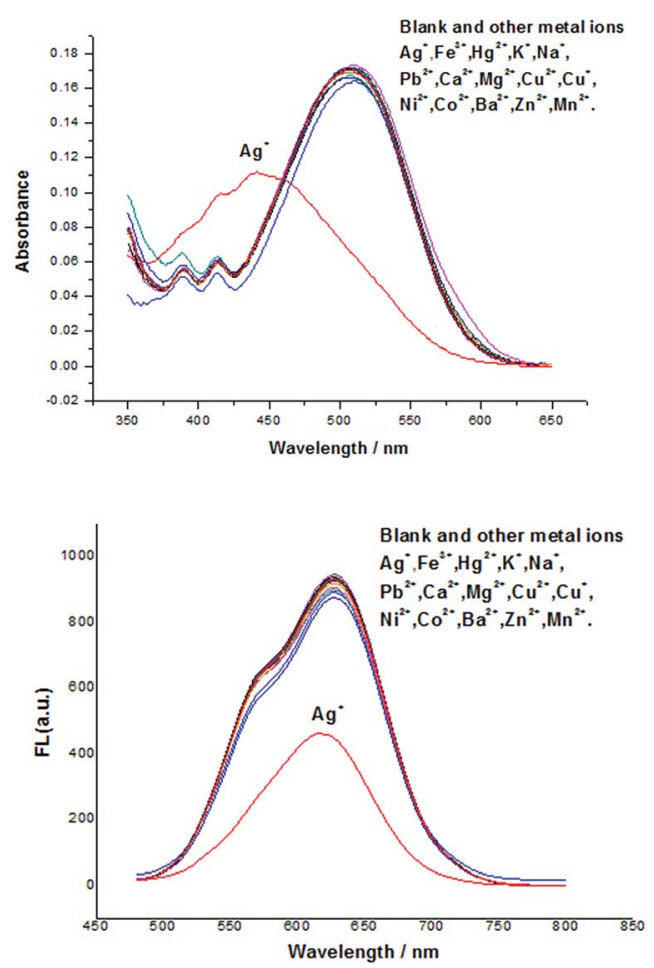

Fig. 1 UV-vis (A) and fluorescence spectral (B) of probe DCPS-1 (5 $\mu \mathrm{M})$ in the presence of $\mathrm{Ag}^{+}$(5 equiv.) and various of other mental ions (10 equiv.) in $\mathrm{MeOH}$ solution at room temperature, $\lambda_{\mathrm{ex}}=460 \mathrm{~nm}$. took place a blue shift from $510 \mathrm{~nm}$ to $441 \mathrm{~nm}$ when $\mathrm{Ag}^{+}$was added, while there was no significant difference of absorption band when other mental ions were added and the color of probe DCPS-1 solution changed from red to yellow obviously when $\mathrm{Ag}^{+}$ was added, while the color of probe DCPS-1 solution without any change when other mental ions were added (Fig. 2).

We further assessed the possible interferences by other ions, competitive experiments were conducted, as shown in Fig. S12, $\dagger$ there was no significant variation in fluorescence intensity of DCPS-1- $\mathrm{Ag}^{+}$solution was observed when other ions were added or not. The above experimental results shown that the probe DCPS-1 have a high selectivity toward to $\mathrm{Ag}^{+}$than other mental ions, so this probe DCPS-1 is suitable for naked-eye detection of $\mathrm{Ag}^{+}$with highly selectivity.

Then the time-dependent absorption and fluorescence intensity changes of probe DCPS-1 $(5 \mu \mathrm{M})$ after adding 5 equivalent of $\mathrm{Ag}^{+}$were tested. As shown in Fig. 3, the absorption band of probe DCPS-1 disappeared soon at $510 \mathrm{~nm}$ after adding $\mathrm{Ag}^{+}$, and a new absorption band appeared at $441 \mathrm{~nm}$, which subdued quickly with incubation time and reached the

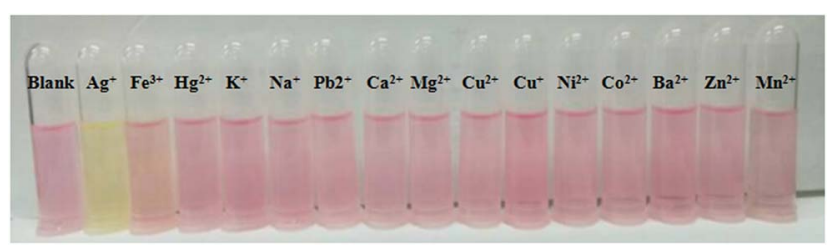

Fig. 2 The color changes of DCPS- 1 solution $(5 \mu \mathrm{M})$ when a various mental ions (10 equiv.) were added in $\mathrm{MeOH}$ solution at room temperature.
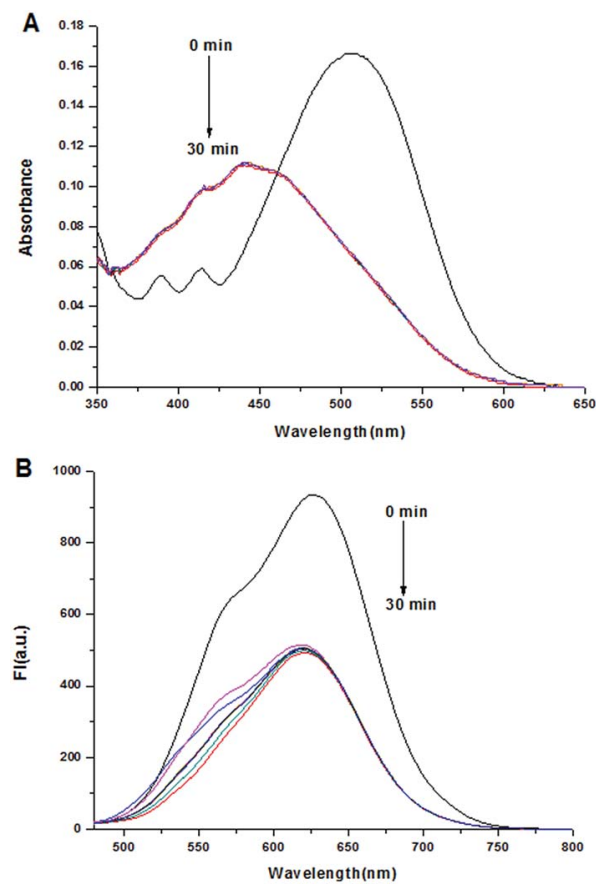

Fig. 3 UV-vis (A) and fluorescence spectral (B) of probe DCPS-1 ( $5 \mu \mathrm{M})$ against time in the presence of $\mathrm{Ag}^{+}$(5 equiv.) in $\mathrm{MeOH}$ solution at room temperature, $\lambda_{\mathrm{ex}}=460 \mathrm{~nm}$. 
minimum values after incubation for $30 \mathrm{~min}$ at room temperature. In the fluorescence spectra, the emission band of probe DCPS-1 at $628 \mathrm{~nm}$ disappeared immediately upon adding $\mathrm{Ag}^{+}$, and a new emission band appeared at approximately $620 \mathrm{~nm}$, over incubation time, the intensity was almost the same, showing that the time for the probe DCPS-1 to form a complex with $\mathrm{Ag}^{+}$was very short, and this characteristic it is very favorable for us to detect $\mathrm{Ag}^{+}$qualitatively and quantitatively. It is also noteworthy that the emission of complex reached the farred to NIR range, which is very attractive for intracellular sensing and imaging.

We further performed UV-vis and fluorescence titration experiments to research the sensing ability of probe DCPS-1 to $\mathrm{Ag}^{+}$(0-5 equiv.). As shown in Fig. 4A, the subdued absorption at $510 \mathrm{~nm}$ and enhancement at $441 \mathrm{~nm}$ could be observed with the increasing $\mathrm{Ag}^{+}$concentrations concomitantly. Moreover, the decreased fluorescence intensity at 620-628 nm can be easily found upon addition of increasing amounts of $\mathrm{Ag}^{+}$(Fig. 4B). As shown in Fig. S9, $\uparrow$ the plots of fluorescence intensity versus $\mathrm{Ag}^{+}$ concentration showed linear correlation in the range of $0-10$ $\mu \mathrm{M}$ and the detection limit for $\mathrm{Ag}^{+}$was deduced to as low as $21.2 \mathrm{nM}(3 \sigma / k)$, it is shown that our probe was highly sensitive to $\mathrm{Ag}^{+}$. In order to study the applicability of DCPS-1 in a real sample, DCPS-1 was used in the detection of $\mathrm{Ag}^{+}$in water samples such as tap water, Pearl River water and waste water, the results shown in Table S1. $\dagger$ In a word, the visual readouts and far-red emission of probe DCPS-1 makes it a powerful tool for sensing in both environment and biology samples.
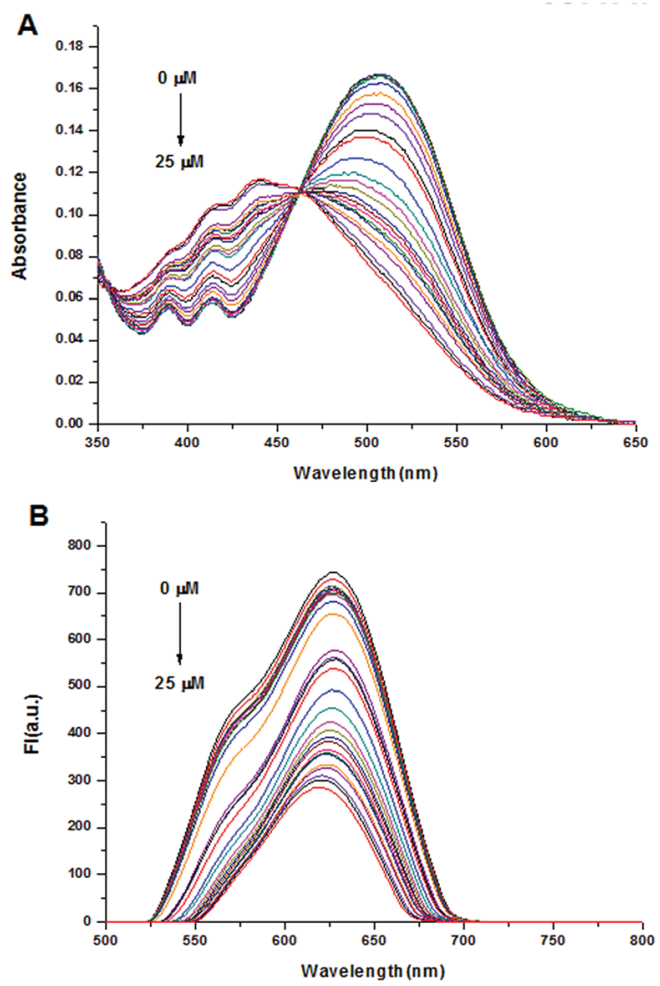

Fig. 4 UV-vis (A) and fluorescent (B) spectroscopic titration of probe DCPS- 1 by stepwise addition of $\mathrm{Ag}^{+}$. Conditions: [probe DCPS-1] $=5$ $\mu \mathrm{M} ; \mathrm{MeOH}, \lambda_{\mathrm{ex}}=460 \mathrm{~nm}$. The spectra were record at $30 \mathrm{~min}$ intervals.
To further research the mechanism of the sensing process, NMR experiments were conducted. As shown in Fig. S8, $\dagger$ In the ${ }^{1} \mathrm{H}$ NMR spectra of probe DCPS-1 and its complex, the chemical shifts of $H_{\mathrm{a}}, H_{\mathrm{b}}, H_{\mathrm{c}}$ and $H_{\mathrm{d}}$ shifted downfield from 2.61, 2.72, 3.61 and 6.77 ppm to $2.76,2.87,3.70$ and 6.81 ppm upon adding $\mathrm{Ag}^{+}$cations, respectively. The electronic withdrawing effect of silver ions can made chemical shifts of hydrogen from high to low field. Reversible experiment was carried out, as shown in Fig. S11. $\dagger$ when added chloride ions to eliminate $\mathrm{Ag}^{+}$, the UV-vis and fluorescence spectral of probe DCPS-1 basic recovery, this result confirmed that DCPS-1 bind to $\mathrm{Ag}^{+}$rather than react with it. In order to research the binding stoichiometry between DCPS-1 and $\mathrm{Ag}^{+}$, a plot of fluorescence intensity versus the molecular fraction of [DCPS-1] $/\left[\mathrm{Ag}^{+}+\right.$DCPS-1] was provided in Fig. 5. It assured that the maximum fluorescence was about 0.5 indicating the $1: 1$ stoichiometry between DCPS-1 and $\mathrm{Ag}^{+}$in the complexes. From the above results, the binding model was proposed for DCPS-1 and $\mathrm{Ag}^{+}$: two $\mathrm{S}$ atom and $\mathrm{N}$ was coordination with $\mathrm{Ag}^{+} .^{35,36}$ Base on the ${ }^{1} \mathrm{H}$ NMR experiment and HRMS spectrum (Fig. S7†), and the binding model was proposed as illustrated in Scheme 1. We calculated the quantum yields of DCPS-1 and $\left[\mathrm{Ag}^{+}+\right.$DCPS-1 $]$ $\left(\varnothing_{\text {DCPS-1 }}=0.56, \varnothing_{\text {DCPS-1 }+\mathrm{Ag}^{+}}=0.34\right)$, this results confirmed that the fluorescence of DCPS-1 quenching occurs when $\mathrm{Ag}^{+}$was added.

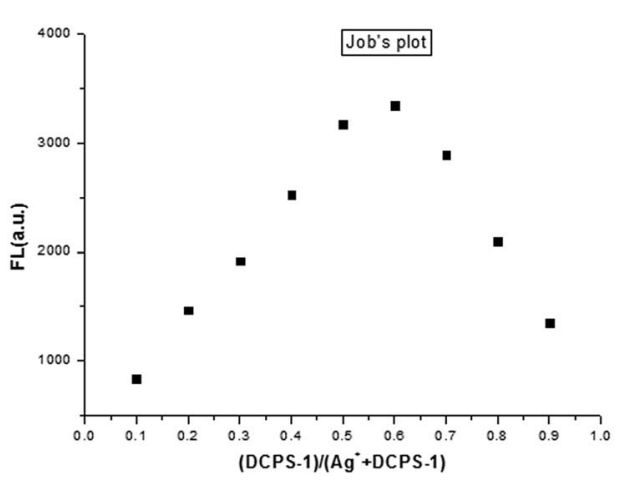

Fig. 5 Job's plot for the complex of DCPS-1 with $\mathrm{Ag}^{+}$in $\mathrm{MeOH}$.

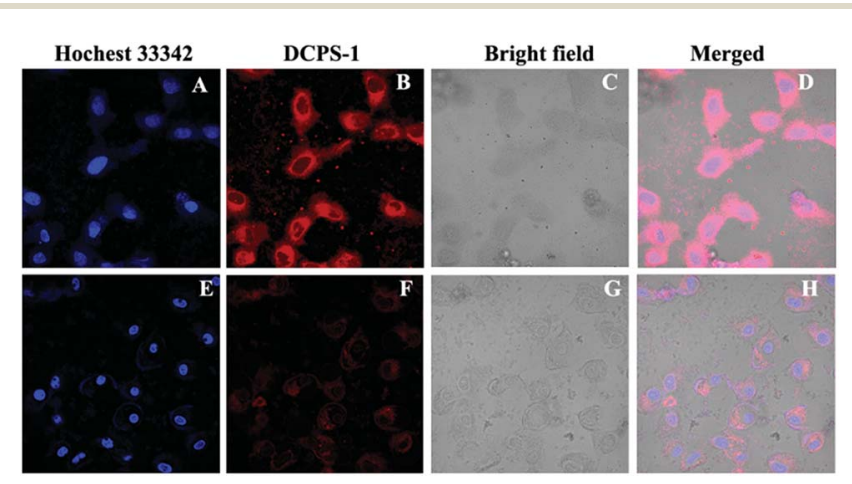

Fig. 6 Confocal fluorescence images of living HeLa cells using a $488 \mathrm{~nm}$ laser. HeLa cells were co-stained with Hoechst 33342 (10 $\mu \mathrm{M})$ and DCPS-1 $(10 \mu \mathrm{M})$, without $(A-D)$ and with $(E-H)$ incubation of $\mathrm{Ag}^{+}(30 \mu \mathrm{M})$ for $30 \mathrm{~min}$. 
Encouraged by the outstanding properties of this probe for the detection of $\mathrm{Ag}^{+}$in solution, the potential intracellular applications of probe DCPS-1 were investigated using confocal laser scanning microscopy. The cytotoxicity of probe DCPS-1 to cells was evaluated using a standard MTT assay. The results indicated that probe DCPS-1 exhibited very low cytotoxicity to living HeLa and 293T cells for $48 \mathrm{~h}$ (Fig. S10†). Living cell imaging assay was performed using HeLa cells. As shown in Fig. 6A-D, co-staining living HeLa cells with Hochest 33342 revealed that DCPS-1 alone exhibited strong fluorescence emission. While, the fluorescence intensity significantly decreased after incubation with $\mathrm{Ag}^{+}$for 30 min (Fig. 6E-H). These results demonstrated that DCPS-1 is a useful tool for the detection of $\mathrm{Ag}^{+}$in both environmental and in living cells.

\section{Conclusions}

In summary, a colorimetric and far-red fluorescent probe DCPS1 for $\mathrm{Ag}^{+}$was successfully developed. The vivid color change and turn-off emission make it simple and visual indicator for $\mathrm{Ag}^{+}$. Besides, probe DCPS-1 also exhibited high specificity and sensitivity, with the detection limit of $21.1 \mathrm{nM}$. Moreover, DCPS$\mathbf{1}$ was applied in the detecting and imaging of $\mathrm{Ag}^{+}$in living cells successfully, which indicated that probe DCPS-1 is suitable for tracking intracellular $\mathrm{Ag}^{+}$species. All these characteristics make it a useful tool for $\mathrm{Ag}^{+}$detection in both environment and biomedical research field.

\section{Conflicts of interest}

There are no conflicts to declare.

\section{Acknowledgements}

This work was financially supported by the National Natural Science Foundation of China (21502056), the Natural Science Foundation of Guangdong Province, China (2016A030310463, 2015A030310490), and the Fundamental Research Funds for the Central Universities (2017MS079).

\section{Notes and references}

1 W. C. Lee, C.-h. Wang, Y. H. Lin, W. C. Shih and T. G. Ong, Org. Lett., 2013, 15, 5358-5361.

2 D. Sarkar, RSC Adv., 2013, 3, 24389-24399.

3 Y.-h. Huang, R. I. Dass, Z.-l. Xing and J. B. Goodenough, Science, 2006, 312, 254-257.

4 S. Biswas, Z. Huang, Y. Choliy, D.-y. Wang, M. Brookhart, K. K. Jespersen and A. S. Goldman, J. Am. Chem. Soc., 2012, 134, 13276-13295.

5 K.-f. Chen, Y. D. Noh, K.-y. Li, S. Komarneni and D.-f. Xue, J. Phys. Chem. C, 2013, 117, 10770-10779.

6 G. I. Hutchings, M. Brustb and H. Schmidbaur, Chem. Soc. Rev., 2008, 37, 1759.

7 K. M. C. Wong and V. W. W. Yam, Coord. Chem. Rev., 2007, 251, 2477.

8 J. H. Schiller and G. Bittner, Clin. Cancer Res., 1999, 5, 4287.
9 H.-y. Tan, J.-g. Liu, L.-f. Zhou, Y.-k. Li, J.-w. Yan and L. Zhang, RSC Adv., 2017, 7, 6583.

10 C. Zhang, J.-f. Guo, A.-m. Ren and D. Wang, RSC Adv., 2017, 7, 49505.

11 J. L. Barriada, A. D. Tappin, E. H. Evans and E. P. Achterberg, TrAC, Trends Anal. Chem., 2007, 26, 809-817.

12 M. N. Croteau, S. K. Misra, S. N. Luoma and E. ValsamiJones, Environ. Sci. Technol., 2011, 45, 6600-6607.

13 S.-s. Huang, S. He, Y. Lu, F.-f. Wei, X.-s. Zeng and L.-c. Zhao, Chem. Commun., 2011, 47, 2408-2410.

14 M. Yamanaka, K. Hara and J. Kudo, Appl. Environ. Microbiol., 2005, 71, 7589.

15 G.-q. Wen, C.-y. Lin, M.-l. Tang, G.-s. Liu, A.-h. Liang and Z.-l. Jiang, RSC Adv., 2013, 3, 1941-1946.

16 Z. Zhen, X.-y. Yang, M.-h. Shen, J.-f. Liu and Y.-g. Yin, J. Environ. Sci., 2015, 35, 62-68.

17 Y. Yang, R. Behra, L. Sigg, P. Fernandez Freire, S. Pillai and K. Schirmer, Nanotoxicology, 2015, 9, 1-10.

18 J.-f. Zhang, Y. Zhou, J. Y. Yoon and J. S. Kim, Chem. Soc. Rev., 2011, 40, 3416-3429.

19 C.-b. Huang, X.-j. Peng, Z.-y. Lin, J.-l. Fan, A.-x. Ren and D.-x. Sun, Sens. Actuators, B, 2008, 133, 113-117.

20 S. Ma, J. He, M.-z. Guo, X.-h. Sun and M.-d. Zheng, RSC Adv., 2016, 6, 106608-106614.

21 K. Van Meel, A. Smekens, M. Behets, P. Kazandjian and R. Van Grieken, Anal. Chem., 2007, 79, 6383-6389.

22 K. M. K. Swamy, H. N. Kim, J. H. Sob, Y. Kim, S. j. Kim and J. Yoon, Chem. Commun., 2009, 1234-1236.

23 C. Huang, X. Peng, Z. Lin, J. Fan, A. Ren and D. Sun, Sens. Actuators, B, 2008, 133, 113.

24 A. Chatteriee, M. Santra, N. Won, S. Kim, J. K. Kim, S. B. Kim and K. H. Ahn, J. Am. Chem. Soc., 2009, 131, 2040.

25 E. U. Akkaya and A. Coskun, J. Am. Chem. Soc., 2005, 127, 10464.

26 L. Yuan, W. Lin, K. Zheng, L. He and W. Huang, Chem. Soc. Rev., 2013, 42, 622-661.

27 Z. Guo, S. Park, J. Yoon and I. Shin, Chem. Soc. Rev., 2014, 43, $16-29$.

28 T. Zhu, J. Du, W. Cao, J. Fan and X. Peng, Ind. Eng. Chem. Res., 2016, 55, 527.

29 G. Dey, P. Gaur, R. Giri and S. Ghosh, Chem. Commun., 2016, $52,1887$.

30 M. Hu, J. Fan, J. Cao, K. Song, H. Zhang, S. Sun and X. Peng, Analyst, 2012, 137, 2107-2111.

31 H.-h. Wang, L. Xue, Y.-y. Qian and H. Jiang, Org. Lett., 2010, 12, 292-295.

32 C. S. Park, J. Y. Lee, E.-j. Kang, J. E. Lee and S. S. Lee, Tetrahedron Lett., 2009, 50, 671-675.

33 L. Liu, D. Zhang, G. Zhang, J. Xiang and D. Zhu, Org. Lett., 2008, 10, 2271-2274.

34 R.-h. Yang, W.-h. Chan, A. W. M. Lee, P.-f. Xia and H.-k. Zhang, J. Am. Chem. Soc., 2003, 125, 2884-2885.

35 L.-q. Li and L.-j. Gao, Spectrochim. Acta, Part A, 2016, 152, 426-430.

36 C. Huang, A. Ren, C. Feng and N. Yang, Sens. Actuators, B, 2010, 151, 236-242. 